\title{
Calixarene- and cavitand-based capsules
}

\author{
Wanda Śliwa \\ Institute of Chemistry and Environmental Protection, Jan Dlugosz University, \\ al. Armii Krajowej 13/15, 42-201 Częstochowa, Poland \\ E-mail:w.sliwa@ajd.czest.pl
}

Dedicated to Professor Edmunds Lukevics on his $70^{\text {th }}$ birthday

\begin{abstract}
In this paper, dimeric capsules are presented. In the first sections, selected examples of covalently bound capsules are described, then species held by hydrogen bonding and coordination with metal ions are characterized. Following chapters concern capsules bound by ionic interactions and van der Waals forces. Lastly, examples of guest-templated capsules are presented. Binding of guests within capsules is described along with application possibilities of these species.
\end{abstract}

Keywords: Binding, calixarene, capsule, cavitand, guest

\section{Table of Contents}

Introduction

1. Covalently Bound Capsules

2. Hydrogen Bonded Capsules

3. Capsules Bound by Metal Coordination

4. Capsules Bound by ionic Interactions

5. Capsules Bound by van der Waal's Interactions

6. Guest-templated Capsules

Conclusions

References 


\section{Introduction}

Capsules formed from calixarenes, as from cavitands, have been intensively studied; due to interesting properties they are a topic of numerous reports. ${ }^{1-3}$ The present review is a continuation of our previous papers concerning calixarenes, ${ }^{4-8}$ resorcinarenes $^{9}$ and cavitands, ${ }^{10,11}$ along with calixarene assemblies ${ }^{12}$ and calixpyrroles. ${ }^{13}$

Capsules are formed by dimerization of calixarenes or cavitands via their covalent linking, ${ }^{14}$ as well as through hydrogen bonds ${ }^{15}$ or metal coordination. ${ }^{16}$ Capsules are of interest in the design of molecular devices ${ }^{17}$ and may serve as microreaction vessels; ${ }^{18,19}$ they are promising for use in separation technologies ${ }^{20}$ and as mimics of enzyme-substrate interactions. ${ }^{21}$

In the first part of the review, capsules covalently linked are presented; they are followed by species held together by hydrogen bonding and coordination with metal ions, then capsules bound by ionic interactions and van der Waals forces are described. In the last part examples of guest-templated capsules are shown. The references are cited mainly from reports appearing since 2005 .

\section{Covalently Bound Capsules}

Covalently bound capsules are a theme of a number of works, some examples will be shown below. In the study of isotope effects, the binding of the capsules (hemicarcerands) 1 with a series of guests 2-8 has been investigated. ${ }^{14}$ The guests had $\mathrm{D}_{4 \mathrm{~h}}$ symmetry (2-4) and $\mathrm{C}_{2 \mathrm{v}}$ symmetry (5-8). The hemicarcerand enables the precise determination of small size differences between two incarcerated guests, even those resulting from their deuteration, by examination of chromatographic properties of both hemicarceplexes formed with these guests.

Investigating the communication of the guest of hemicarceplexes $\mathbf{1 b}$-guests with an external chromatographic stationary phase, a large increase in the HPLC retention factor k' with guest size was observed. The value of k' was the lowest for the fastest (1) $\mathbf{1} \cdot$ benzene) and highest for the slowest (1) $\mathbf{7}$-methoxyphthalide) eluting hemicarceplex.

It was found that $\mathrm{ln} \mathrm{k}$, which is proportional to the change in free energy $\Delta \mathrm{G}$, upon transferring a hemicarceplex from the mobile to stationary phase, correlates almost linearly with the guest length for hemicarceplexes having nearly $\mathrm{D}_{4 \mathrm{~h}}$ symmetry (hemicarceplexes with guests 2-4).

The reaction of capsule 9a with 10 and butane-1,4-dimesylate in the presence of $\mathrm{Cs}_{2} \mathrm{CO}_{3}$ in HMPA and the brief irradiation of formed $\mathbf{9 b} \cdot 10$ in $\mathrm{CH}_{2} \mathrm{Cl}_{2}$ affords $\mathbf{9 b} \cdot \mathbf{1 1}$; in this way it was shown that singlet phenylnitrene undergoes a thermal ring-expansion to give cyclic ketenimine 11, its polymerization being prevented by the surrounding host. ${ }^{22}$ This procedure allowed the NMR spectroscopic characterization of $\mathbf{1 1}$. 
Capsules 12b-f served as reaction vessels for thermal decomposition of diazirines 13-15. ${ }^{23}$ Diazirines undergo fragmentation to carbenes and nitrogen or weakly bound carbenenitrogen complexes, which form diazo compounds or carbene reaction products.

The thermal decomposition of $\mathbf{1 3}$ encapsulated in 12e was accelerated due to the stabilization of transition state by dispersion forces. However, the decomposition of $\mathbf{1 4}$ was not affected by encapsulation in 12e and the decomposition rate of $\mathbf{1 5}$ encapsulated in $\mathbf{1 2 d}$ decreased.

In order to explain the influence of capsule on the decomposition rate of 13-15, the shape of the host was slightly altered through variation of one linker; in this way, the center-to-center distance between two cavitands of the capsule could be changed.

Hemicarceplex 12e·13 was obtained by stirring $12 \mathrm{e}$ with 13 in $\mathrm{CDCl}_{2} \mathrm{CDCl}_{2}$. Hemicarceplexes $12 \mathrm{~b} \cdot 14, \mathbf{1 2 c} \cdot 14$ and $\mathbf{1 2 f} \cdot 14$ were obtained by reacting the diol host 12a with linkers 16 or 17, respectively, and $\mathrm{Cs}_{2} \mathrm{CO}_{3}$ in HMPA with excess of 14 .

The dissociation of obtained hemicarceplexes is slow enough at elevated temperature to study the thermal decomposition of the guest. Comparing diazirine decomposition processes in the bulk phase with that in the inner phase, it was observed that the hemicarcerand stabilizes the inner-phase transition states enthalpically and destabilizes the transition states entropically.

The complexation properties of hemicarcerands 18 and 19 were investigated. On the basis of AM1 calculations for host, guest and host-guest complexes a criterion for predicting guest encapsulation was determined. ${ }^{24}$ The barriers to the exit of DMF and furan from hemicarceplexes $\mathbf{1 8 b} \cdot \mathrm{DMF}$ and 18b·furan have been computed, and the synthesis of the hemicarceplex $\mathbf{1 8 b} \cdot$ furan has been made.
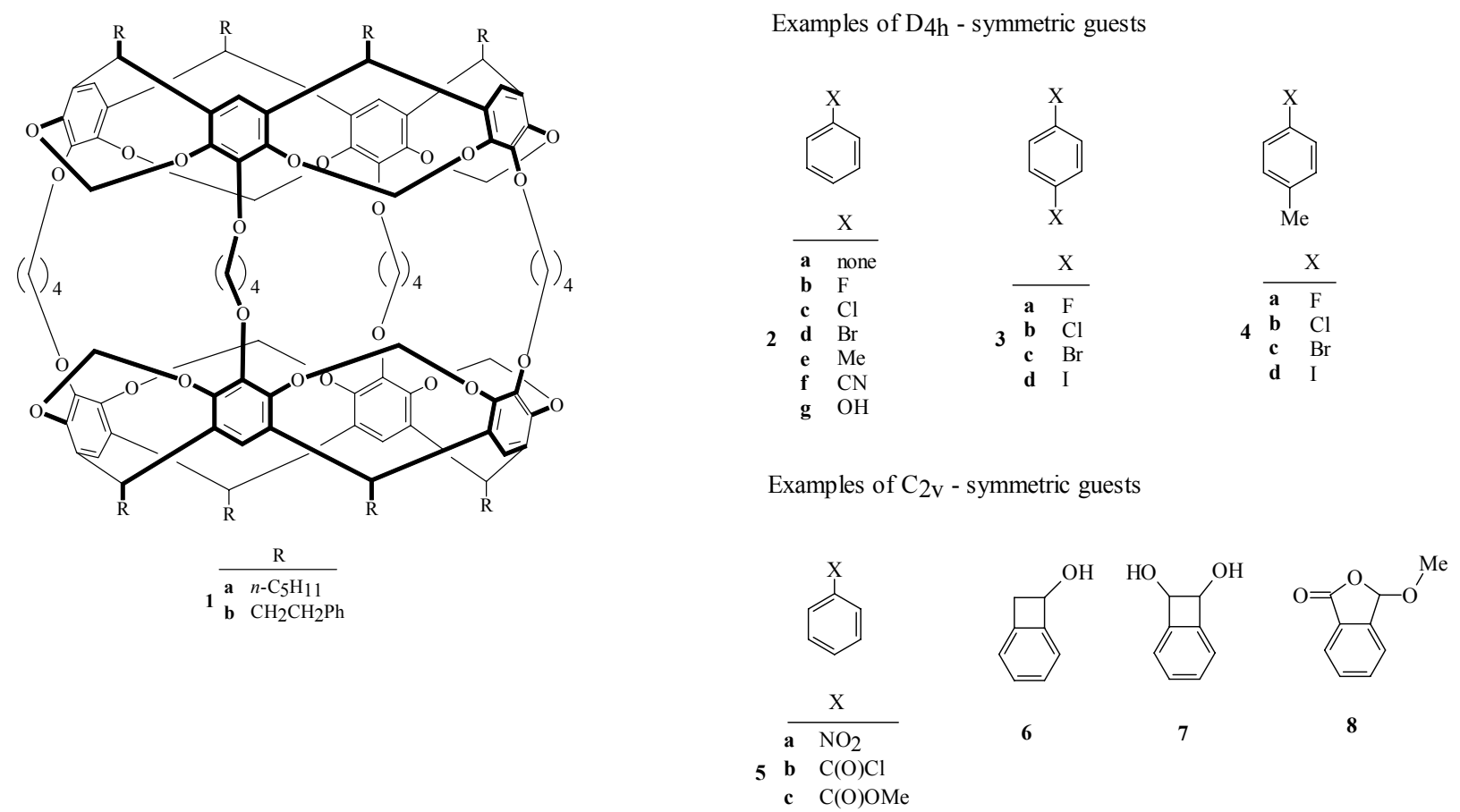


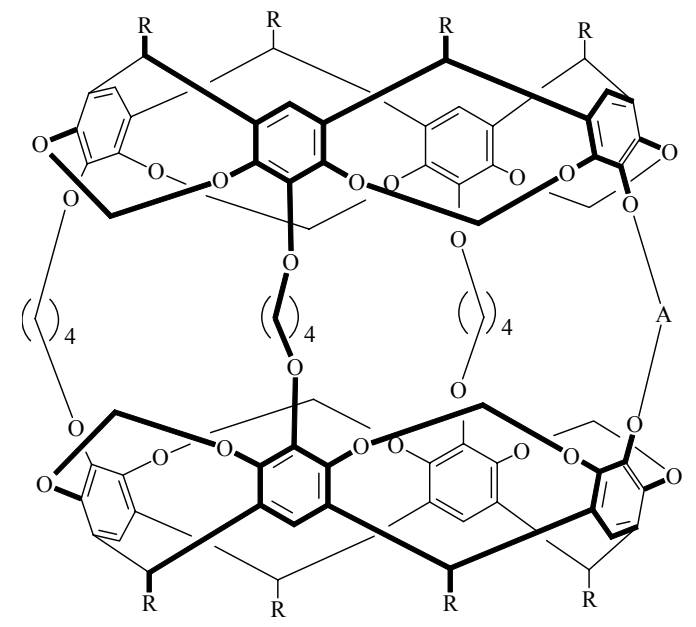

$\mathrm{R}=n-\mathrm{C}_{5} \mathrm{H}_{11}$

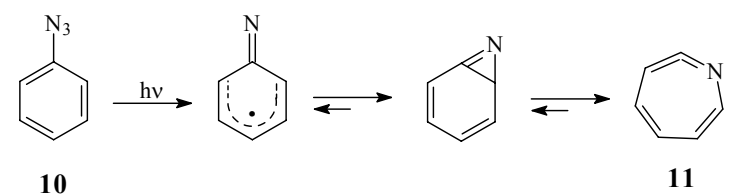

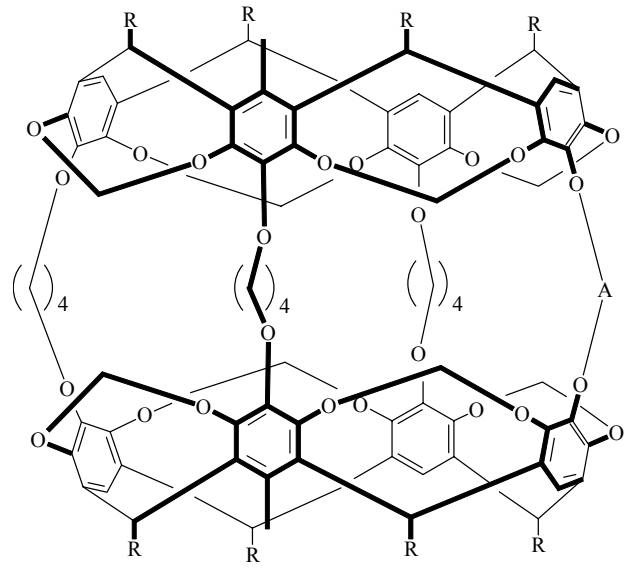

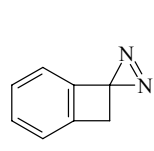

13

TsO- $\left(\mathrm{CH}_{2}\right)_{\mathrm{n}}-\mathrm{OTs}$

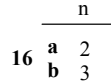

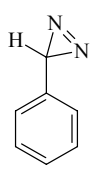

14
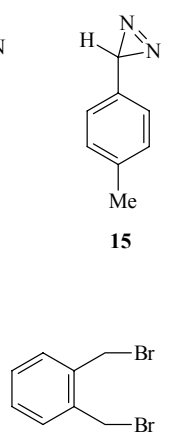

17

$\mathrm{R}=\mathrm{CH}_{2} \mathrm{CH}_{2} \mathrm{Ph}$

$$
\begin{array}{ll} 
& \multicolumn{1}{c}{\mathrm{A}} \\
\hline \mathbf{a} & 2 \mathrm{H} \\
\mathbf{b} & \left(\mathrm{CH}_{2}\right)_{2} \\
\mathbf{c} & \left(\mathrm{CH}_{2}\right)_{3} \\
\mathbf{d} & \left(\mathrm{CH}_{2}\right)_{4} \\
\mathbf{e} & \left(\mathrm{CH}_{2}\right) 5 \\
\mathbf{f} & \mathrm{CH}_{2} \\
&
\end{array}
$$



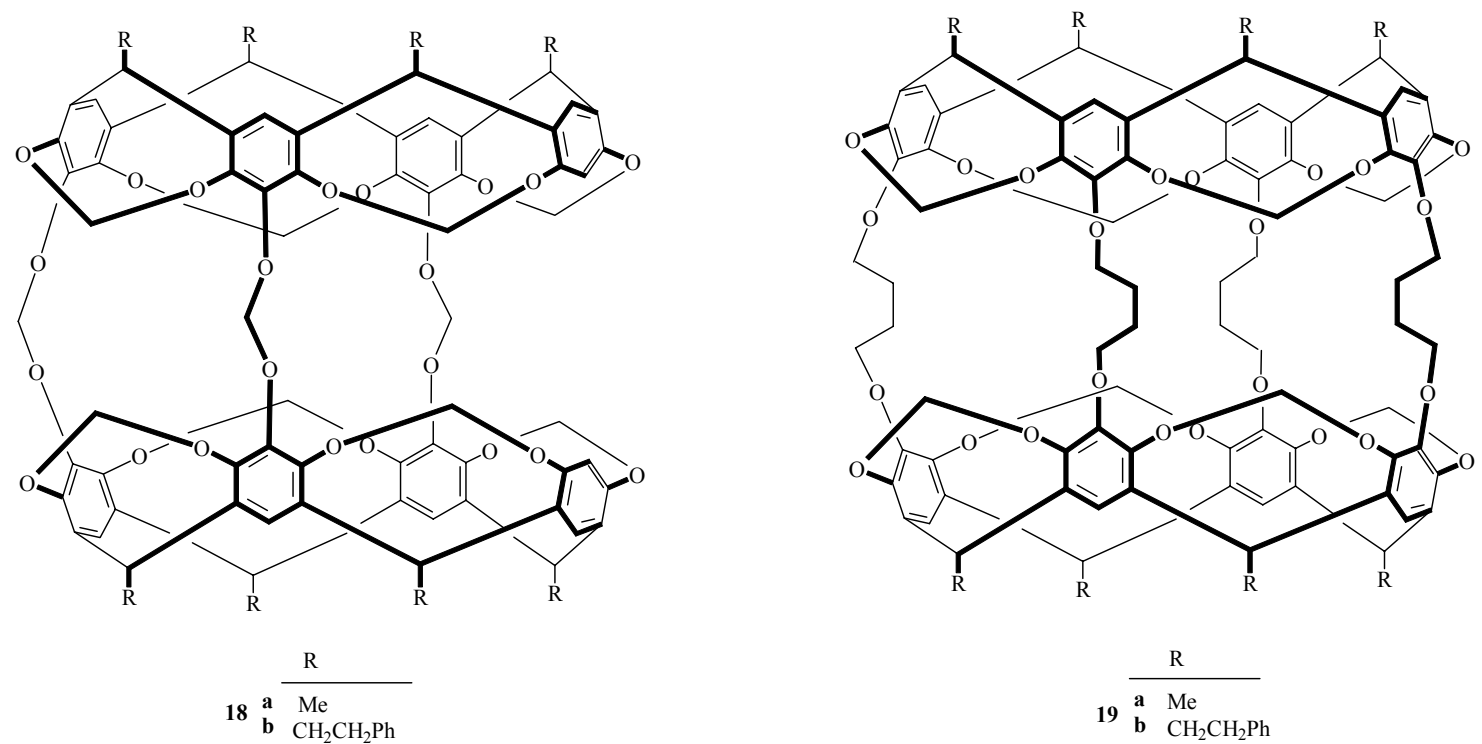

\section{Scheme 1}

It was found that the capsule $\mathbf{2 0}_{2}$ formed by the assembly of two molecules of cavitand $\mathbf{2 0}$ may enclose guest molecules in aqueous solution; as such naphthalene, anthracene, and tetracene have been chosen. ${ }^{25}$

Two molecules of either naphthalene or anthracene may be held within the capsule, this fact resulting in the enhancement of their excimer emission. However, two anthracene molecules encapsulated in $\mathbf{2 0}_{2}$ cannot achieve the geometry required for dimerization; therefore, the photodimerization of anthracene is impossible.

Since the tetracene molecule is larger, its one molecule only can be encapsulated in $\mathbf{2 0}_{2}$, and only the monomer emission is observed. The above results show that the inclusion of the guest within the cavity of the capsule $\mathbf{2 0}_{2}$ can suppress photochemical pathways that are normally favored in solution.

Mono-, bis-, and tris-hemicarceplexes 21-23 containing pyrazine as a guest have been obtained. ${ }^{26}$ It was observed that they show twistomerisomerism. In bis- and tris-hemicarceplex 22 and 23 two diastereomers exist; A and B are chiral and achiral conformers of 22, respectively.

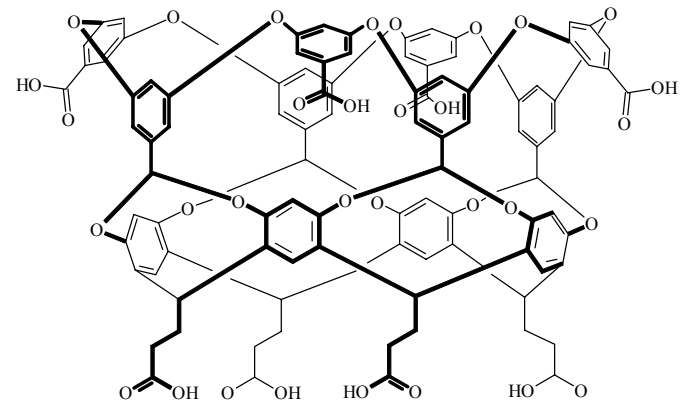

20 


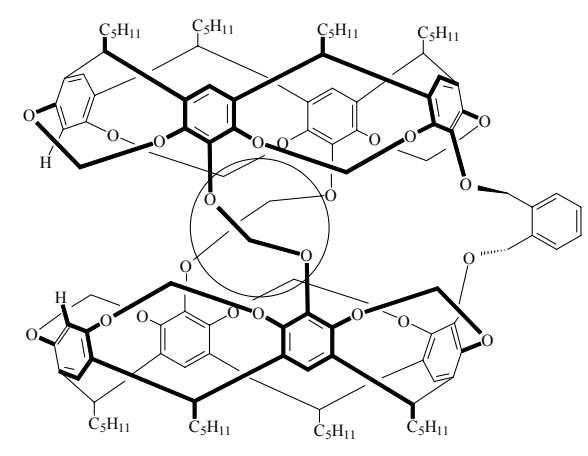

21

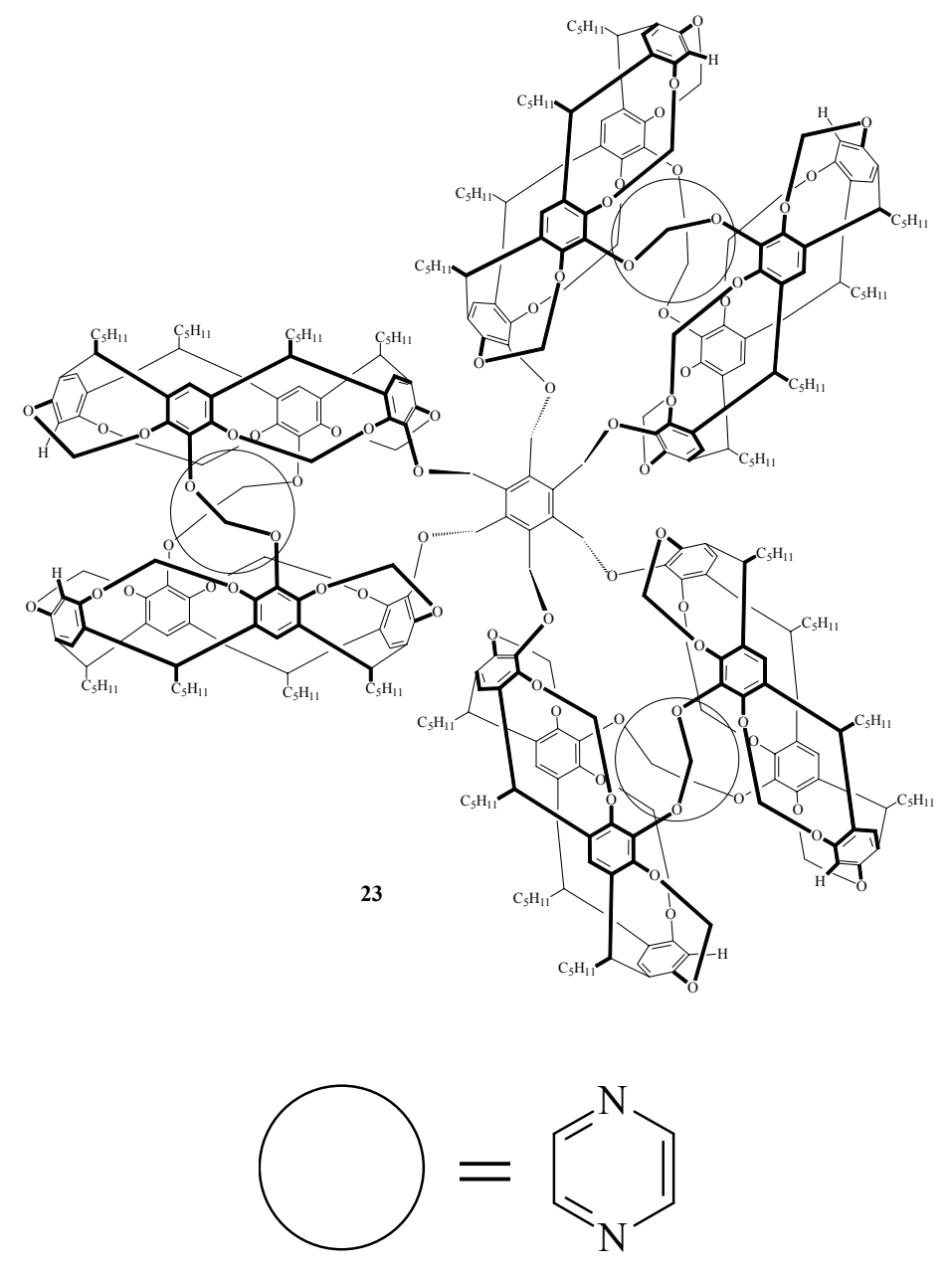



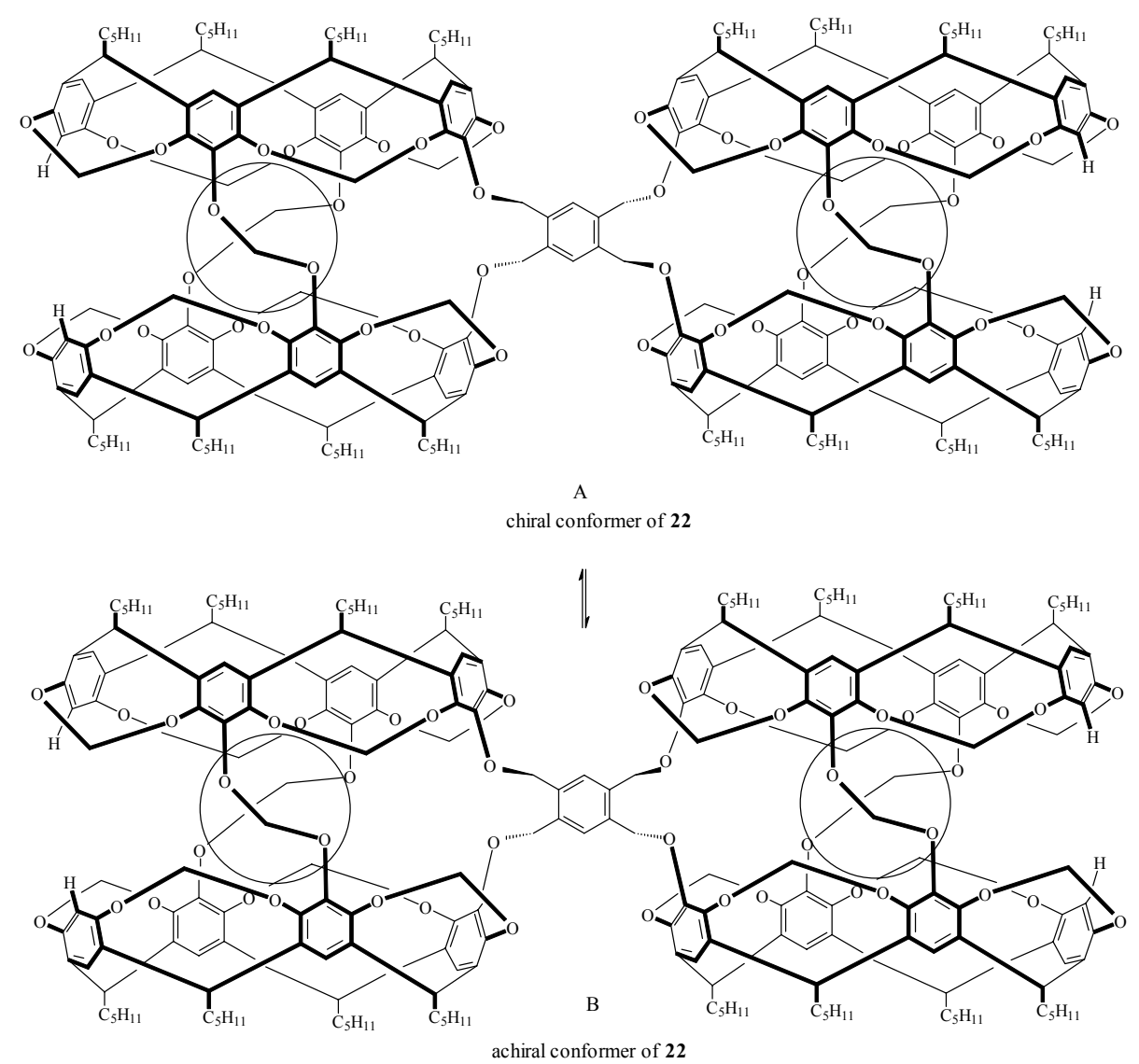

\section{Scheme 2}

\section{Hydrogen-bonded Capsules}

The complexation of resorcinarenes $\mathbf{2 4}$ with small quaternary alkyl ammonium salts, e.g. $\mathbf{2 5}^{+} \mathrm{Br}^{-}$ affords hydrogen-bonded dimeric capsules upon crystallization from relatively hydrophilic solvents, e.g. alcohols. The complexation of $\mathbf{2 4}$ with doubly protonated and $N, N^{\prime}$-quaternized DABCO derivatives $\mathbf{2 6}^{2+}-\mathbf{2 8}^{2+}$ has been studied. ${ }^{27}$

The crystallization of $\mathbf{2 4 b}$ with $25^{+} \mathrm{Br}^{-}$i.e. $\left(\mathrm{Me}^{+}{ }_{4} \mathrm{NBr}\right.$ ) from aqueous $\mathrm{MeOH}$ affords a dimeric capsule, $\mathbf{2 4} \mathbf{b}_{2}$ enclosing $\mathbf{2 5}^{+}$, which is stabilized by four intramolecular hydrogen bonds between phenolic hydroxyl groups. The confined cation $\mathbf{2 5}^{+}$, as well as the co-crystallized methanol molecules and bromide ion are disordered. Complexes form hydrogen-bonded ribbons, mediated by the bromide ions.

It was observed that $\mathbf{2 4 a}$ forms with $\mathbf{2 6}^{2+}$ and $\mathbf{2 7}^{2+}$ dimeric capsules embedding $\mathbf{2 6}^{2+}$ or $\mathbf{2 7 ^ { 2 + }}$, respectively; $\mathbf{2 4} \mathbf{c}_{2}$ forms dimeric capsule with $\mathbf{2 8}^{2+}$, in which $\mathbf{2 8}^{2+}$ interacts with two resorcinarene moieties via its phenyl groups. In dimeric capsules $\mathbf{2 4} \mathbf{a}_{2}$ and $\mathbf{2 4} \mathbf{c}_{2}$ the guests $\mathbf{2 6}^{2+}$ $\mathbf{2 8}^{2+}$ are severely disordered, as in the case of capsule $\mathbf{2 4} \mathbf{b}_{2}$ with $\mathbf{2 5}^{+}$. 
In the study of capsules, it was established that resorcinarene 29 treated in ethanol with terpyridine $\mathbf{3 0}$ and $o$-carborane affords the complex $\left[(\text { ortho-carborane })_{2} \subset(\mathbf{2 9})_{2}(\mathbf{3 0})_{4}\right] \cdot($ orthocarborane). ${ }^{28}$ In this complex, the capsule held together by four terpyridine units through sixteen $\mathrm{OH}$... $\mathrm{N}$ hydrogen bonds completely includes two ortho-carborane molecules.

Tetra-acrylamido calix[4]arenes 31, having cone all-trans conformation undergo dimerization in nonpolar solvents to give capsules, which may include small organic molecules. ${ }^{29}$ It was found that $\mathbf{3 1 b}_{2}$ is a hydrogen bonded dimer; dimerization occurs via eight hydrogen bonds $(\mathrm{NH} . . . \mathrm{O}=\mathrm{C})$ between $\mathrm{C}=\mathrm{O}$ and $\mathrm{N}-\mathrm{H}$ groups of opposing acrylamides. The electron-poor $p$-CN-aryl group interacts face-to-face with electron-rich aromatic moiety of the calixarene enhancing the stabilization.

The addition of benzene to a $\mathrm{CDCl}_{3}$ solution of $\mathbf{3 1 \mathbf { b } _ { 2 }}$ leads to inclusion of benzene molecule. The pesticides thiuram $\mathbf{3 2}$ and triazine $\mathbf{3 3}$ may also be encapsulated into $\mathbf{3 1} \mathbf{b}_{2}$. It should be pointed out that the encapsulation is irreversible.

When inclusion complex $\mathbf{3 1 b}_{2} \cdot \mathbf{3 3}$ is treated with 32, no guest exchange occurs; no guest exchange occurs also when $\mathbf{3 1 b}_{2} \cdot \mathbf{3 2}$ is treated with $\mathbf{3 3}$. It was observed that the equimolar mixture of 31a and 31b in $\mathrm{CDCl}_{3}$ affords heterodimeric capsule 31a·31b; mixtures of 31a with 31c and of 31b with 31c also give heterodimeric capsules 31a·31c and 31b·31c.

Calixarenes 34 substituted by urea groups at their wide rims have been synthesized. When the chloroform solution of $\mathbf{3 4 a}$ was treated with tetraethylammonium bromide or hexafluorophosphate, the formation of dimeric capsules $34 \mathbf{a}_{2}$ including $\mathrm{Et}_{4} \mathrm{~N}^{+}$ions occurred. Similar behavior was observed for $\mathbf{3 4 b} \mathbf{b}-\mathbf{d}$, this fact indicating that the size of the amide groups does not influence dimerization. Halide anions may be hydrogen-bonded to capsules.

It was found that calixarenes 34a and 34c form with $\mathrm{Et}_{4} \mathrm{~N}^{+} \mathrm{Br}^{-}$a single heterodimer $\mathrm{Et}_{4} \mathrm{~N}^{+} \cdot \mathbf{3 4 a} \cdot \mathbf{3 4} \mathbf{c} \cdot \mathrm{Br}^{-}$, coexisting with the two homodimers ${ }^{30}$.
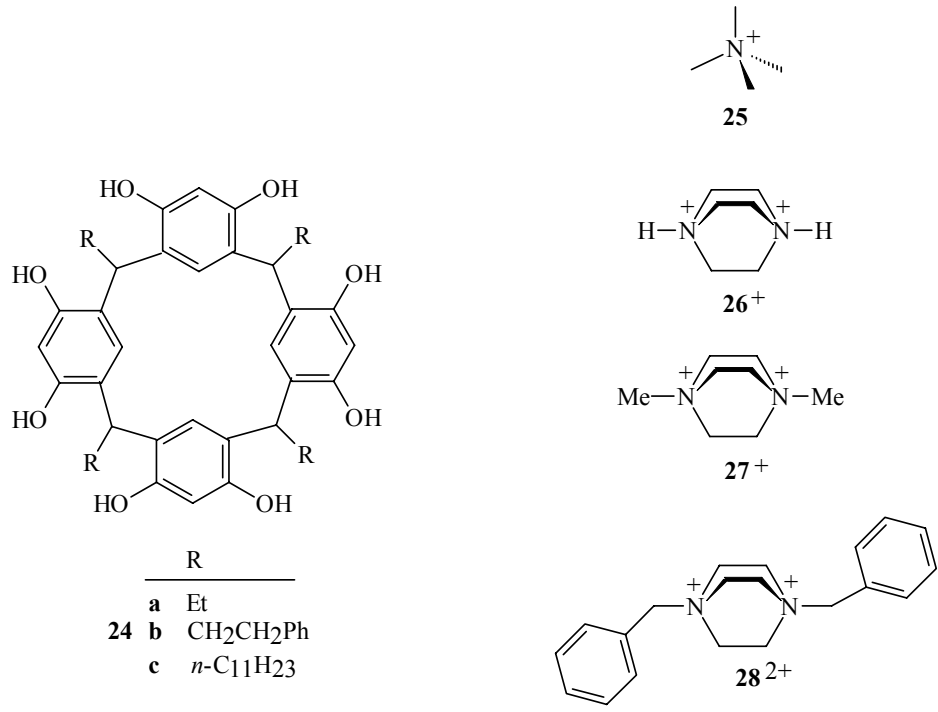


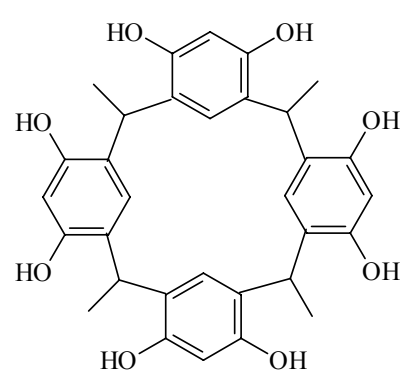

29

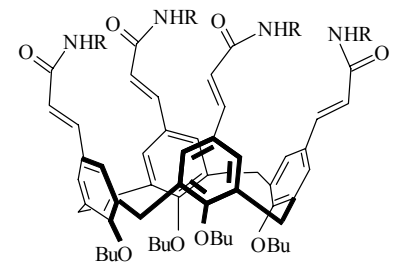

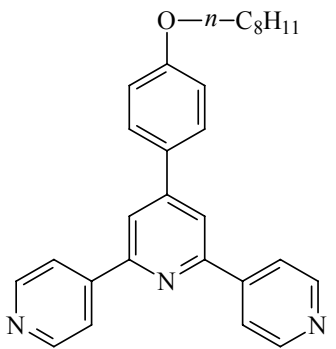

30

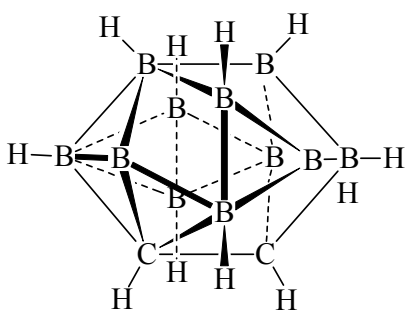

ortho-carborane

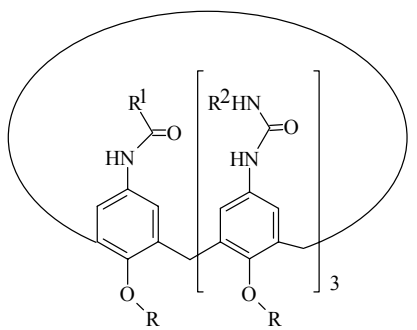

$\mathrm{R}=n-\mathrm{C}_{5} \mathrm{H}_{11}$

$$
\begin{array}{rll} 
& \mathrm{R} 1 & \multicolumn{1}{c}{\mathrm{R}^{2}} \\
\hline \mathbf{a} & \mathrm{Me} & 4-\mathrm{C}_{6} \mathrm{H}_{4} \mathrm{Me} \\
\mathbf{b} & \mathrm{Me} & n-\mathrm{C}_{6} \mathrm{H}_{13} \\
\mathbf{3} & \mathrm{Et} & 4-\mathrm{C}_{6} \mathrm{H}_{4} \mathrm{Me} \\
\mathbf{d} & n-\mathrm{Bu} & 4-\mathrm{C}_{6} \mathrm{H}_{4} \mathrm{Me}
\end{array}
$$
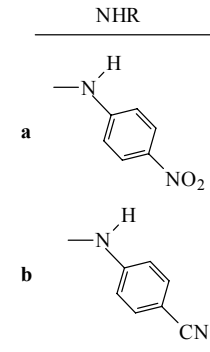

31
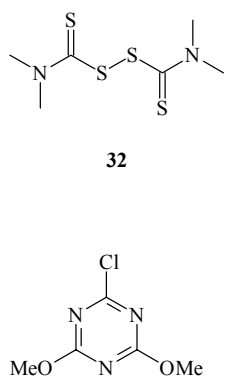

33

\section{Scheme 3}

\section{Capsules bound by metal coordination}

Among capsules bound by metal coordination, the homo- and heterocapsules are known, the latter being less studied as the former ones. Below some examples of both types of species will be presented.

Cavitand 35 reacts with $\mathrm{AgBF}_{4}$ to give a stable $\mathrm{D}_{4}$-symmetric capsule 36. The silver ion coordinates two bipyridyl groups in a tetrahedral fashion. Capsule $\mathbf{3 6}$ may incorporate rigid guests 37b-39; complexes with 39b and 39c are stable since 39b and 39c have the best complementary molecular length among the guests used. The $K_{a}$ values decrease in the order 39c $>39 b>38>39 a>37 b .^{31,32}$

When a mixture of acetic acid and $\mathbf{3 7 a}$ is added to solution of $\mathbf{3 6}$, the hetero dimer of acetic acid and 37a in the capsule is formed; the same behavior was observed for propionic acid and 37a.

When acetic acid, propionic acid, and $\mathbf{3 7 a}$ were added to $\mathbf{3 6}$, the exclusive formation of the hetero dimer of acetic acid and $\mathbf{3 7 a}$ occurred. The calculation of structures has shown that both 
hetero dimers - acetic acid·37a and propionic acid·37a very well fit inside $\mathbf{3 6}$, and the methyl groups of acetic and propionic acids point down to the ends of the cavity, enabling $\mathrm{CH} / \pi$ interactions. However, the more acidic methyl group of acetic acid creates better $\mathrm{CH} / \pi$ interactions than methyl group of propionic acid, therefore the heterodimer acetic acid $\mathbf{3 7} \mathbf{a}$ is favored over propionic acid·37a.

It was observed that the reaction of cavitand 40, cobalt (II) ions and a guest leads to the formation of a capsule including the guest, i.e. 41 $\supset$ guest. A series of organic compounds were used as guest molecules; the guest encapsulation preference decreases in the order: anisole $>p$ xylene $>$ toluene $>$ styrene $>$ benzene $>m$-xylene $>o$-xylene. ${ }^{33}$ The existing selectivity of the guest inclusion should be emphasized, for example $p$-xylene is preferred over toluene which is preferred over benzene, this fact resulting from the pointing of methyl groups of xylene and toluene into the poles of the capsule, enabling formation of $\mathrm{C}-\mathrm{H}$-aryl interactions.

The reaction of cavitand $\mathbf{4 2}$ with palladium and platinum complexes $\mathbf{4 3}$ results in the selfassembly affording capsules 44 incorporating $\mathrm{CF}_{3} \mathrm{SO}_{3}{ }^{-}$anion. The kinetic stability of 44 and their anion encapsulation was studied by PGSE (pulsed field gradient spin-echo), NOE (nuclear Overhauser effect) and EXSY (exchange spectroscopy) NMR techniques. It was found that the kinetic stability of capsules $\mathbf{4 4}$ is solvent dependent. ${ }^{34,35}$

It was established that cavitand 45 reacts with 43 in $\mathrm{CHCl}_{3} / \mathrm{MeOH}$ to give the capsule 46. When in this process the $\mathrm{MeNO}_{2}$ is used as a solvent, the reaction leads to the dynamic equilibrium of $\mathbf{4 6}$ and deep cavitand $47 .^{36}$

The selective self-assembling of homo- and heterocapsules via metal coordination of cavitands has been studied; ${ }^{37,38}$ this process is controlled by the balance between kinetic and thermodynamic stabilities of capsules. It should be pointed out that heterocapsules are not so common as homocapsules.

The mixture of cavitands 48 and 49 treated with $43 \mathrm{a}$ or $43 \mathrm{~b}$ affords thermodynamically stable heterocapsules 50a or 50b, respectively. The Pt-NCPh bond is thermodynamically and kinetically less stable than Pt-pyridine bond; therefore, the homocapsule $\mathbf{5 1}$ in $\mathrm{CDCl}_{3}$ at room temperature gradually underwent ligand exchange with $\mathbf{4 8}$ to give a mixture of $\mathbf{5 0 b}$ and free 49.

The treatment of a mixture of $\mathbf{5 2}$ and $\mathbf{5 3}$ in $\mathrm{CDCl}_{3}$ with $\mathbf{4 3 a}$ at room temperature leads to the formation of kinetically and thermodynamically the most stable homocapsule 54a and the most labile homocapsule 55a. Since the coordination ability of $\mathbf{5 2}$ is much higher than that of 53, the homocapsule 54a forms prior to homocapsule 55a. Initially the formation of 54a based on kinetic control is the driving force of self-assembly, and 55a is only the byproduct. However, upon heating to $50^{\circ} \mathrm{C}$ the heterocapsule 56a is formed; the product is a 1:1:1 mixture of 54a, 55a, and 56a.

The treatment of a mixture of $\mathbf{5 2}$ and $\mathbf{5 3}$ with $\mathbf{4 3 b}$ leads to the formation of homocapsules $\mathbf{5 4 b}$ and 55b along with the heterocapsule 56b. It should be pointed out that 54b and 55b are stable even at $50^{\circ} \mathrm{C}$. 


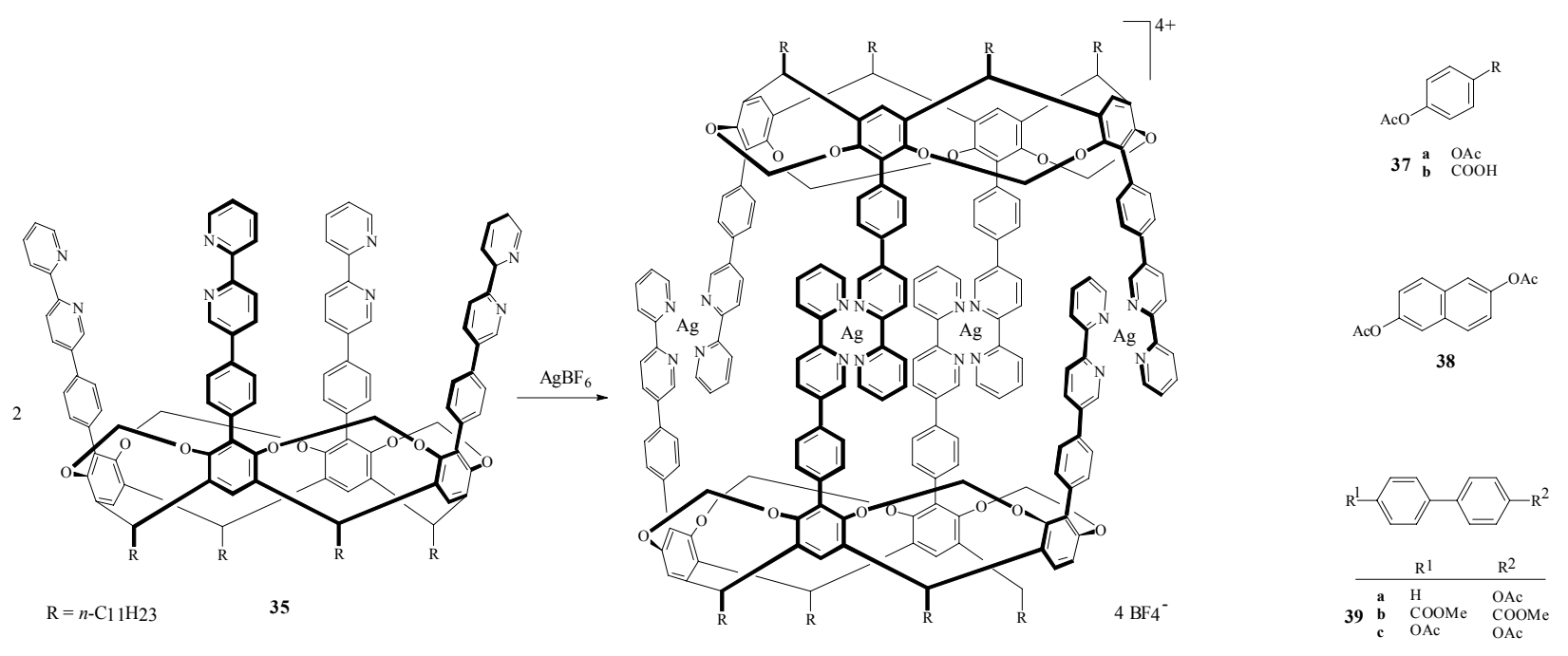

36

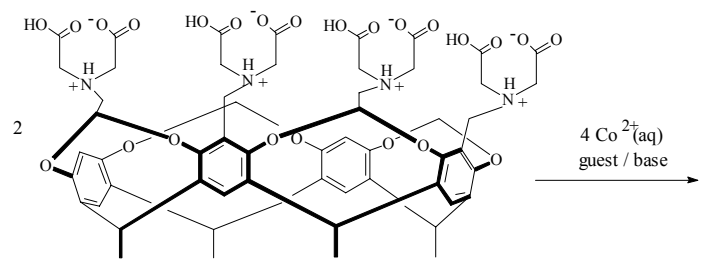

40

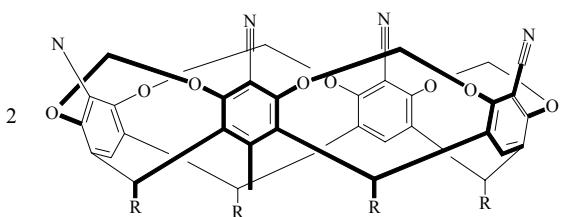

$\mathrm{R}=n-\mathrm{C}_{6} \mathrm{H}_{13}, n-\mathrm{C}_{11} \mathrm{H}_{2}$

42

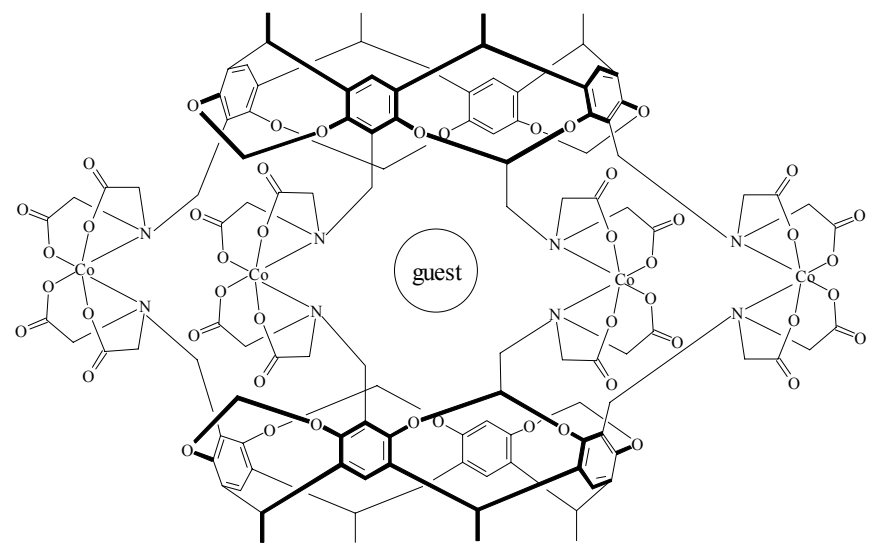

$41>$ guest
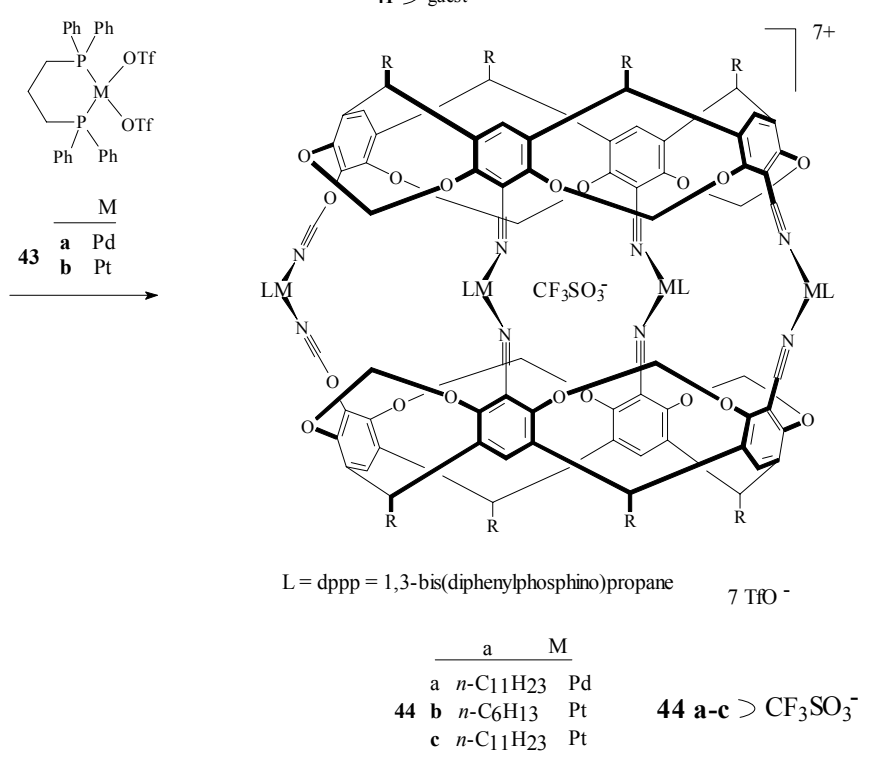

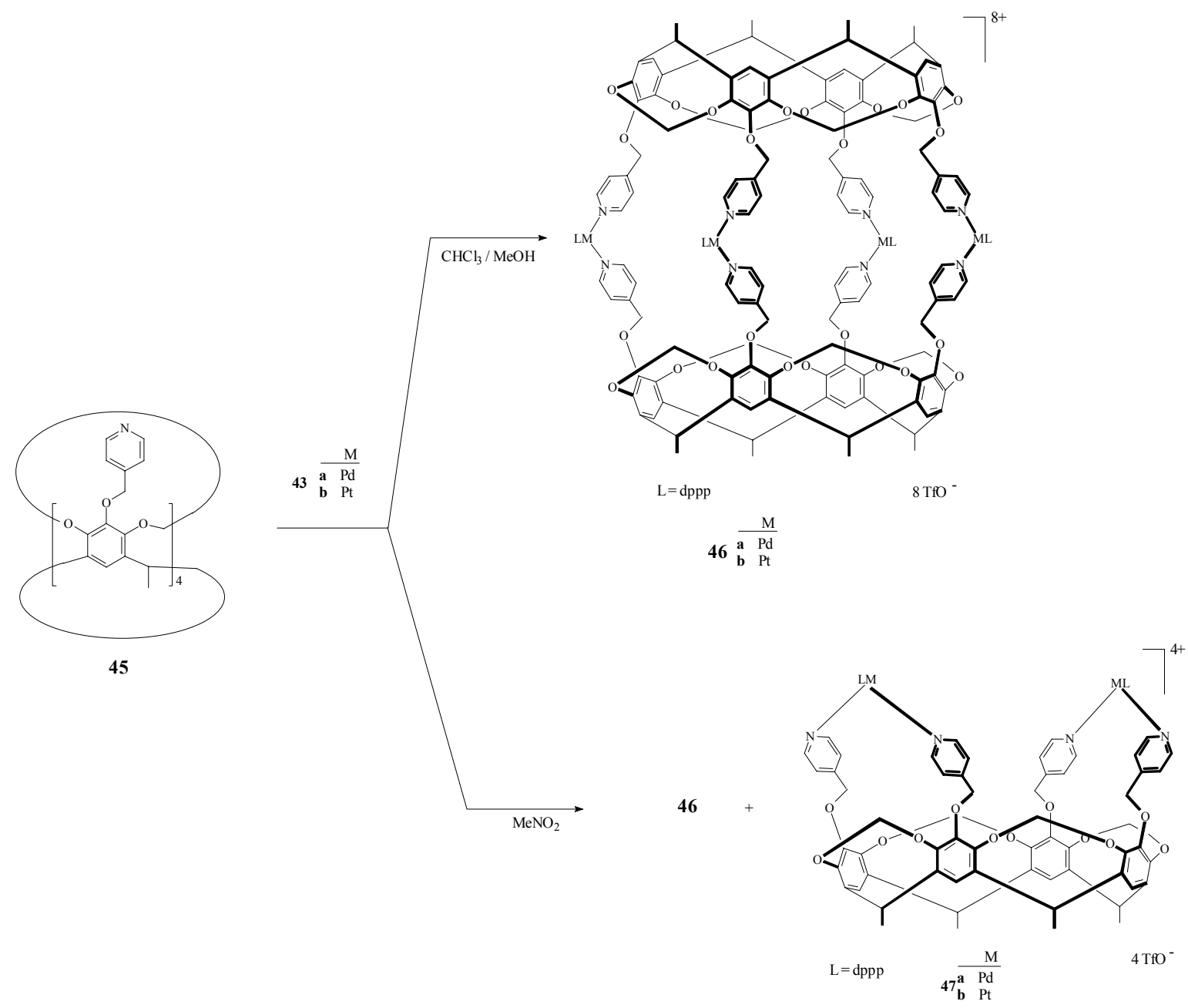

Scheme 4

By heating at $50{ }^{\circ} \mathrm{C}$, the increase of 54b was observed; lastly 56b was converted completely into homocapsules 54b and 55b. The fact that only 54b and 55b exist at the final thermodynamic equilibrium shows that the average thermodynamic stability of $\mathbf{5 4 b}$ and $\mathbf{5 5 b}$ is much higher than the thermodynamic stability of $\mathbf{5 6 b}$. 

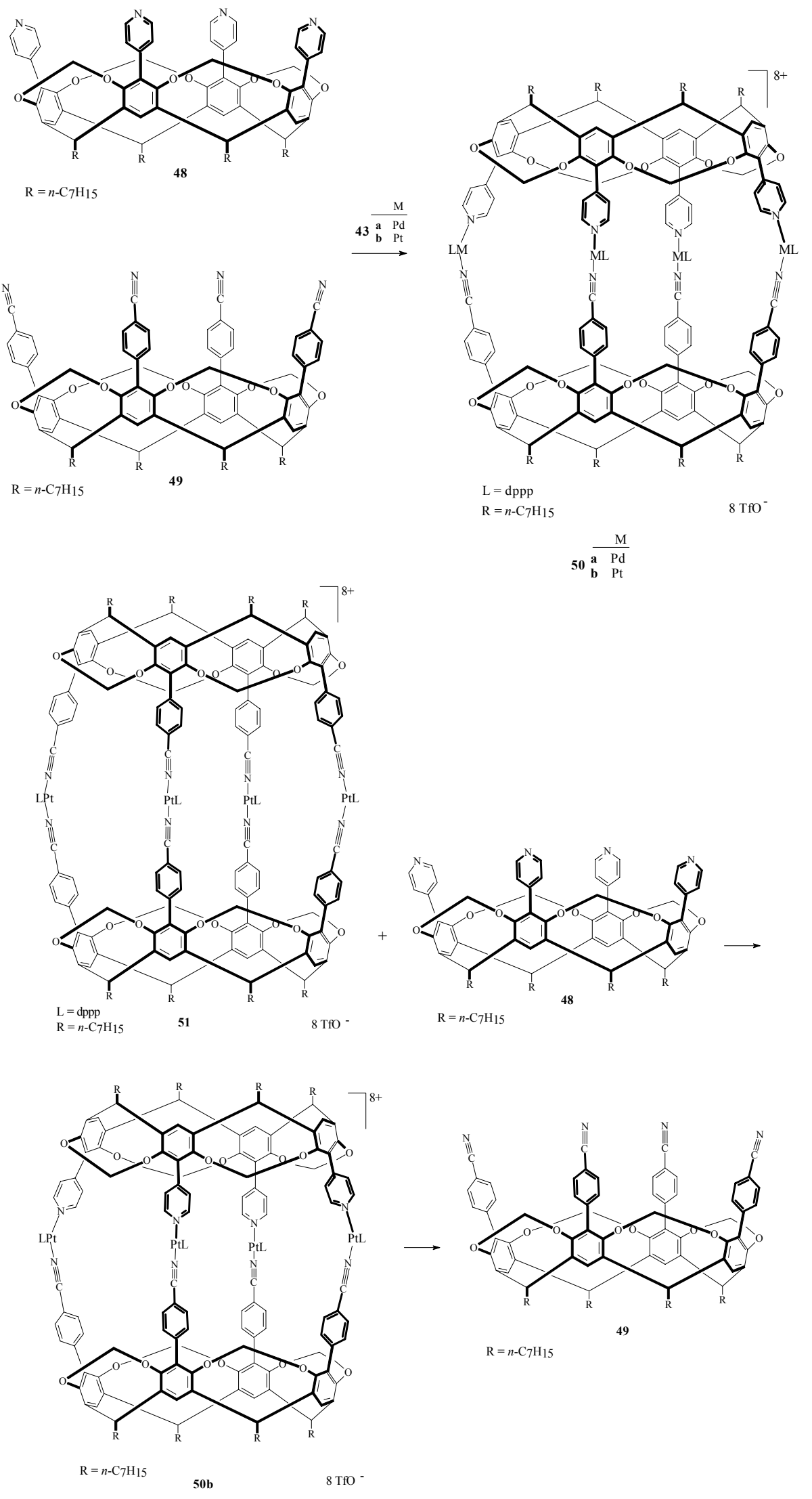


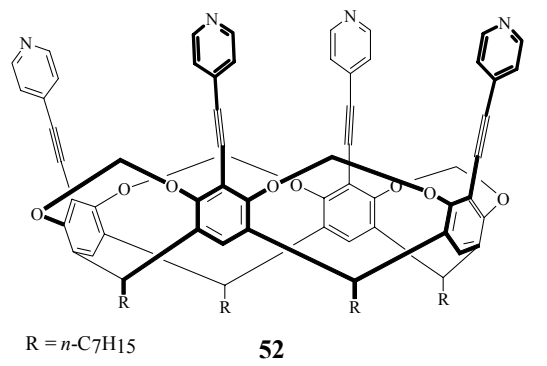

$\underset{43}{\stackrel{\mathrm{b}}{\mathrm{a}} \underset{\mathrm{Pd}}{\mathrm{Pd}}} \stackrel{\mathrm{M}}{\longrightarrow}$

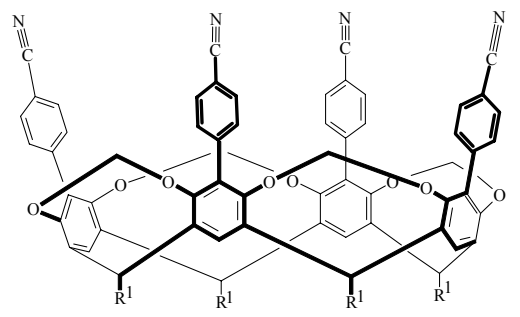

53

$\mathrm{R} 1=n-\mathrm{C}_{11} \mathrm{H}_{23}$

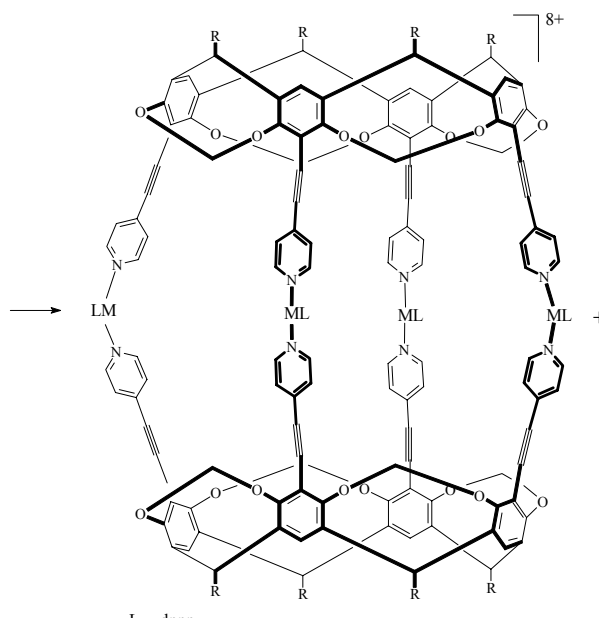

$\mathrm{L}=\mathrm{dppp}$
$\mathrm{R}=n-\mathrm{C} 7 \mathrm{H} 15$

$54 \begin{array}{lll}\underset{b}{\mathbf{a}} & \mathrm{Pd} \\ \mathrm{b} & \mathrm{Pt}\end{array}$

$8 \mathrm{TfO}^{-}-n-\mathrm{C}_{11} \mathrm{H}_{23}$
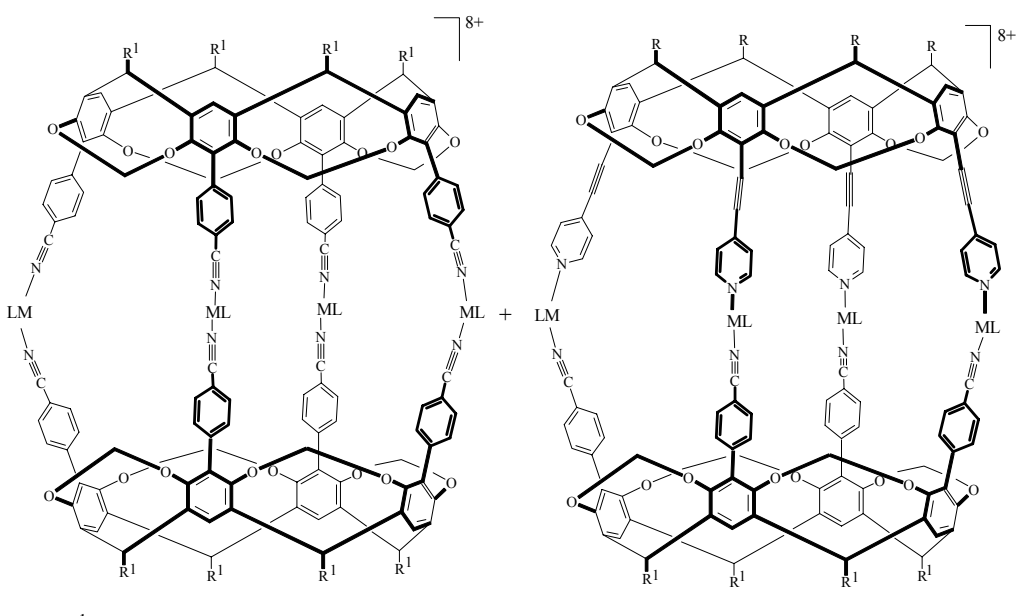

$\begin{array}{lll}\mathrm{R}=n-\mathrm{C}_{7} \mathrm{H}_{15} & \frac{\mathrm{M}}{\mathrm{R} 1=n-\mathrm{C}_{11} \mathrm{H}_{23}} \quad \mathbf{5 6} \\ \mathbf{b} & \mathbf{P} & \mathrm{Pt}\end{array}$

\section{Scheme 5}

\section{Capsules bound by ionic interactions}

The strong ionic interactions, albeit often existing in biological molecular recognition and artificial molecular building, are rather rarely used in formation of capsules; some examples of such species will be given below.

Self-assembly between oppositely charged calixarenes $\mathbf{5 7}$ and $\mathbf{5 8}$ in polar solvents like $\mathrm{MeOH} / \mathrm{H}_{2} \mathrm{O}$ affords capsules formed by multiple ionic interactions of amidinium moieties of $\mathbf{5 7}$ with sulfonate, carboxylic and phosphonate groups of 58. ${ }^{39}$ The association constants for 
capsules 57.58a-c (varying between $10^{3}-10^{6} \mathrm{M}^{-1}$ ) have been determined using ITC (isothermal titration calorimetry).

The ionic interactions between amidinium groups of $\mathbf{5 7}$ and amino acidic residues of $\mathbf{5 9}$ lead to formation of water-soluble capsules $\mathbf{5 7 \cdot 5 9 a}$ and $\mathbf{5 7 \cdot 5 9 b} .^{40}$ The results of ITC allow the estimation of the influence of the size of the amino acid side chains in 59a,b and of the distance of the carboxylic groups from calixarene scaffold in the self-assembly process.

Capsule 57.59a is an effective host for charged species, such as $N$-methylquinuclidinium cation 60 as well as neutral molecules, such as 6-amino-2-methylquinoline 61 in water. Molecular docking, a computational method enabling the rapid evaluation of steric and electrostatic complementarity of potential guest molecules with a host, was applied to indentify possible guest molecules for capsule 57·59a.

\section{Capsules bound by van der Waals interactions}

Capsules, covalently linked by metal coordination or hydrogen bonding have been studied more than those formed from components that interact by van der Waals forces. ${ }^{41}$ Such capsules are not sufficiently stable in solution since solvation forces may exceed van der Waals interactions. However, these interactions are the only source of stabilization of capsules in the solid state; since these interactions are weak, such nanocontainers have the flexibility allowing the capture and release of the guest without destroying the crystal lattice. Guest exchange in such solid matrices is important for their applications in separation science and transport of active species.

The formation of large capsules, which have the flexibility allowing the guest exchange, was studied. It was found that calixarene $\mathbf{6 2}$ forms hydrophobic capsule $\mathbf{6 2} 2$ bound by van der Waals interactions and is able to enclose a variety of guests; the capsule is robust enough to capture large guests at room temperature. ${ }^{42}$

Crystals obtained from a solution of $\mathbf{6 2}$ in $\mathrm{CHCl}_{3}$ have the molecules of $\mathbf{6 2}$ arranged in tailto-tail pairs; the formed hydrophobic dimeric capsules $\mathbf{6 2} 2$, contain four molecules of $\mathrm{CHCl}_{3}$. Complex $62_{2} \cdot 4 \mathrm{CHCl}_{3}$ is, however, thermally unstable in that it instantly releases one $\mathrm{CHCl}_{3}$ molecule, even below room temperature. The heating to $80{ }^{\circ} \mathrm{C}$ results in the loss of two next $\mathrm{CHCl}_{3}$ molecules; the fourth $\mathrm{CHCl}_{3}$ molecule is removed at ca $180{ }^{\circ} \mathrm{C}$.

Since $\mathbf{6 2}_{2} \cdot 4 \mathrm{CHCl}_{3}$ is not very stable, it was anticipated that the replacement of the guest $\mathrm{CHCl}_{3}$ by another guest, e.g. dibenzyl ketone (DBK) may give a more stable structure. The size of DBK is suitable for the cavity of the capsule $\mathbf{6 2}_{2}$. For this purpose, crystals of complex $\mathbf{6 2}_{2} \cdot 4 \mathrm{CHCl}_{3}$ were placed in a saturated solution of $\mathbf{6 2}$ in DBK; this process leads to replacement of some $\mathrm{CHCl}_{3}$ molecules by $\mathrm{DBK}$ without destroying the crystals. The formed complex is capsule $\mathbf{6 2}_{2}$ containing two different guests, $\mathrm{CHCl}_{3}$ and $\mathrm{DBK}$, i.e. it is $\mathbf{6 2}_{2} \cdot \mathrm{CHCl}_{3} \cdot \mathrm{DBK}$.

The TGA results show that this complex releases at $140{ }^{\circ} \mathrm{C}$ the residual $\mathrm{CHCl}_{3}$ molecule affording complex consisting of capsule $\mathbf{6 2}_{2}$ incorporating only $\mathrm{DBK}$, i.e. $\mathbf{6 2}_{2} \cdot \mathrm{DBK}$; DBK leaves the capsule upon heating to $c a .200{ }^{\circ} \mathrm{C}$. The release of $\mathrm{CHCl}_{3}$ from $\mathbf{6 2}_{2} \cdot \mathrm{CHCl}_{3} \cdot \mathrm{DBK}$ proceeds 
without destroying the crystal lattice; this behavior is different from that of $62_{2} \cdot 4 \mathrm{CHCl}_{3}$, in which removal of only two $\mathrm{CHCl}_{3}$ molecules destroyed the crystal lattice.

The phototransformation of cis- and trans-stilbene inside capsule $\mathbf{6 2}_{2}$ bound by van der Waals interactions has been investigated. ${ }^{43-45}$

In bulk solution, stilbenes undergo a reversible cis/trans isomerization; cis-stilbene upon cyclization forms dihydrophenanthrene 63, which upon oxidation afforded phenanthrene 64; trans-stilbene, however, underwent dimerization to give tetraphenylcyclobutanes $\mathbf{6 5}$ and $\mathbf{6 6}$.

It was observed that the slow evaporation of solvent from the $\mathrm{CHCl}_{3}$ solution of $\mathbf{6 2}$ and cis-stilbene affords crystals in which calixarene pairs are arranged into capsules $\mathbf{6 2}_{2}$ containing two molecules of cis-stilbene (complex A). Complex A is thermally unstable; the TGA experiments indicate that one cis-stilbene molecule leaves the capsule cavity at $60-120{ }^{\circ} \mathrm{C}$ yielding complex $\mathrm{B}$, i.e. capsule $\mathbf{6 2} 2$ containing one molecule of cis-stilbene.

The slow cooling of a solution of calixarene $\mathbf{6 2}$ and trans-stilbene in ethanol afforded the crystalline complex $\mathrm{C}$ consisting of capsules $\mathbf{6 2}_{2}$ containing two trans-stilbene molecules and capsules $62_{2}$ containing only one trans-stilbene molecule. The TGA results showed the release of one molecule of trans-stilbene to give the complex consisting of capsules $\mathbf{6 2}_{2}$ containing only one molecule of trans-stilbene.

Complexes A, B and C were irradiated by UV light (320-390 nm). The irradiation of the complex A gave rise to three photochemical reactions, which occur in the bulk solution, among them, the cis/trans isomerization being the fastest process. Since the situation of two transstilbene molecules in the capsule $\mathbf{6 2}_{2}$ at an appropriate distance to undergo dimerization is not probable, the yields of 65 and 66 are low.

Irradiation of complex B leads to cis/trans isomerization followed by cyclization of cisstilbene to phenanthrene 64; dimeric products 65 and 66 were not formed confirming that the capsule $\mathbf{6 2} 2$ contains only one molecule of cis-stilbene.

Irradiation of complex $C$ occurs in a similar way in that only trace amounts of $\mathbf{6 5}$ and $\mathbf{6 6}$ confirmed that in complex $\mathrm{C}$, capsule $\mathbf{6 2} 2$ contains only one molecule of trans-stilbene.

The above results show that capsule $\mathbf{6 2}_{2}$ is sufficiently robust to keep reagents close to each other and allowing their interaction. The crystals of complexes A-C remained intact after irradiation and could be investigated by single-crystal XRD. This stability is of interest in their usefulness in biological processes. 

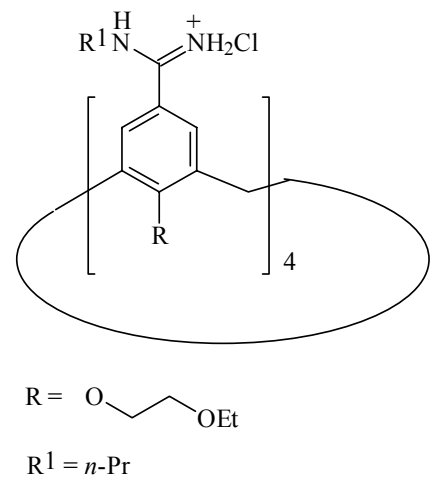

57
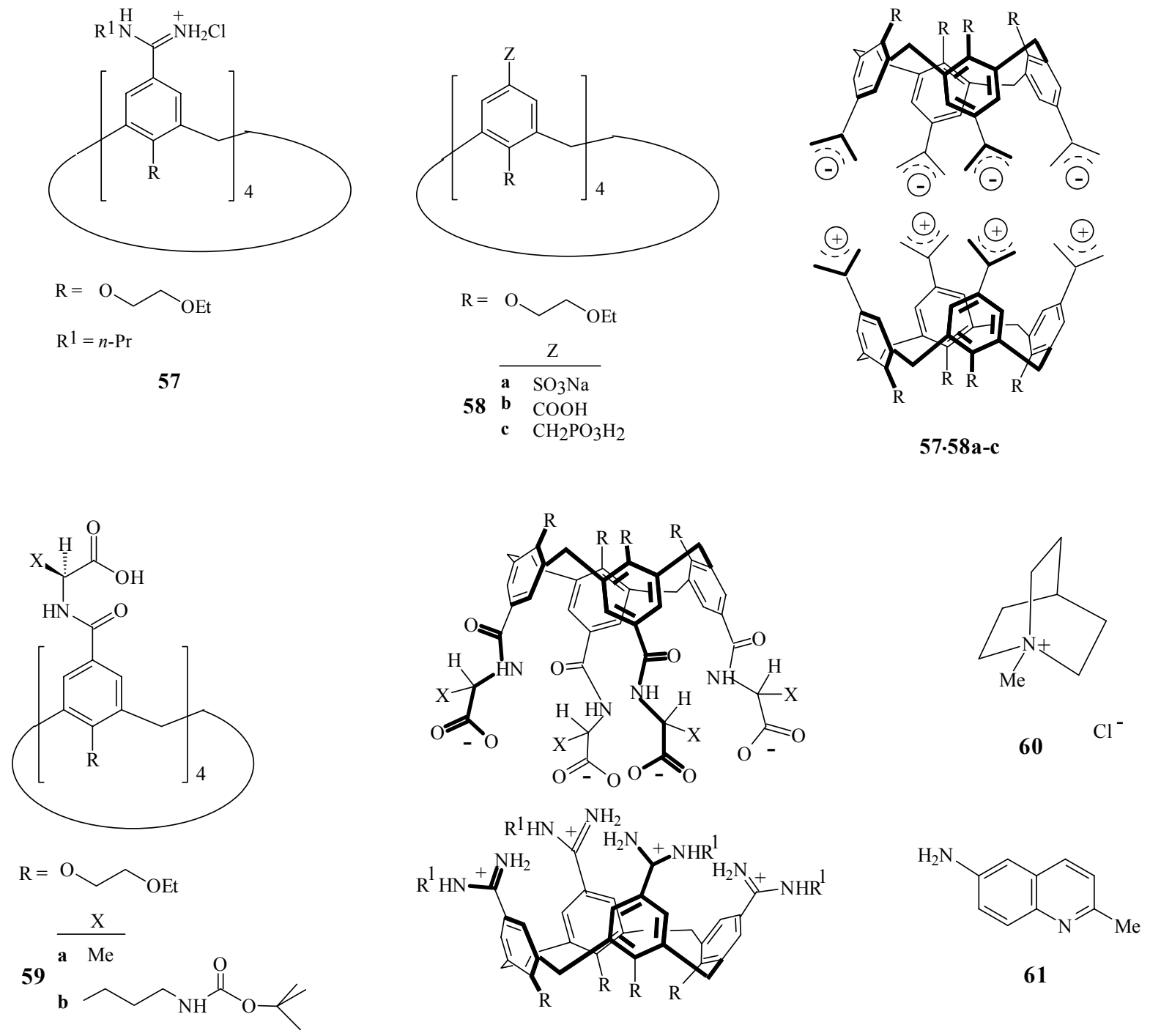

57.59a,b 


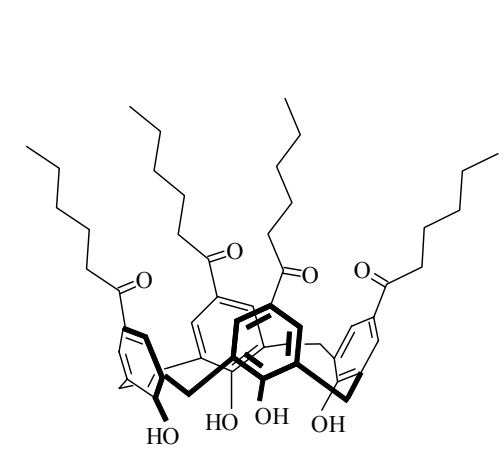

62

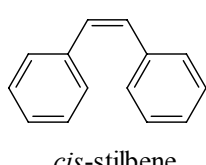

cis-stilbene

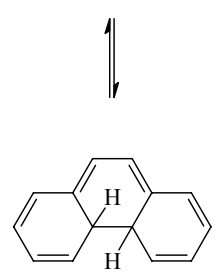

63

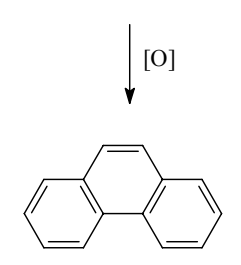

64

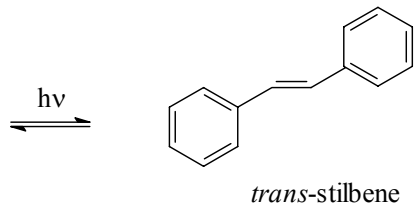

trans-stilbene

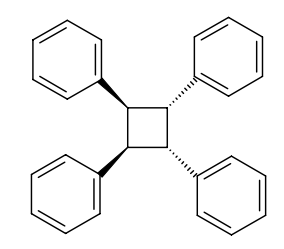

65

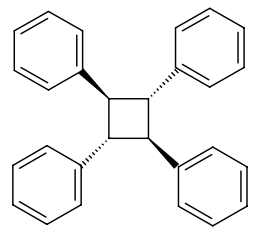

66

\section{Scheme 6}

\section{Guest-templated Capsules}

It was found that calixarene $\mathbf{6 7}$ with anions forms 2:1 complexes, in which anion serves as a template for dimerization of two molecules of $67 .^{46}$ It is an interesting example of anion-induced dimerization of 67; two molecules of $\mathbf{6 7}$ are interconnected by an anion, which is bound within two urea moieties of the dimer.

The formation of complex $67_{2}$ anion does not depend on the geometry of anions; spherical $\left(\mathrm{Cl}^{-}, \mathrm{Br}^{-}, \mathrm{I}^{-}\right)$and nonspherical $\left(\mathrm{NO}_{3}^{-}, \mathrm{AcO}^{-}, \mathrm{BzO}^{-}\right)$anions were bound in the dimeric capsule $67_{2}$.

Cavitands 68 and 69 in the presence of guest form the assembly heterocapsule $70 \supset$ guest. As guests, nonsymmetric $p$-disubstituted benzene derivatives 71 were used. The ability of the guest to induce the formation of the assembly 70 $\supset$ guest decreases in the order 71e $>$ 71b $>$ 71d $>$ 71c $>$ 71a. The halogen atoms of these guests are situated in the cavitand $69 .{ }^{47,48}$

Cavitands 72 and 73 in solvents $\mathrm{G}[\mathrm{G}=N, N$-dimethylformamide (DMF) or $N, N$ dimethylacetamide (DMA)] afford carceplexes $74 \supset \mathrm{DMF}$ and $74 \supset \mathrm{DMA}{ }^{49}$ It is of interest that the free capsule, i.e. carcerand $\mathbf{7 4}$ could not be obtained. When the second, non-interacting guest, e.g. $\mathrm{MeCN}$, is added to $74 \supset \mathrm{DMF}$, the paired carceroisomers $74 \supset(\mathrm{DMF}+\mathrm{MeCN})$ are formed.

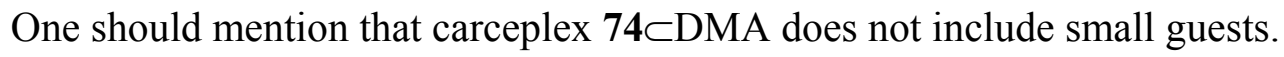


The second guest may reversibly enter and escape through the portals of the carcerand. The fast movement of the first guest (DMF) is hindered by reversible inclusion of second guest $(\mathrm{MeCN})$. The orientation of guests in two carceroisomers $74 \supset(\mathrm{DMF}+\mathrm{MeCN})$, major and minor ones shows the pairwise dipole complementarity between the $\mathrm{C}=\mathrm{O}$ and $-\mathrm{C} \equiv \mathrm{N}$ groups of two paired guests.

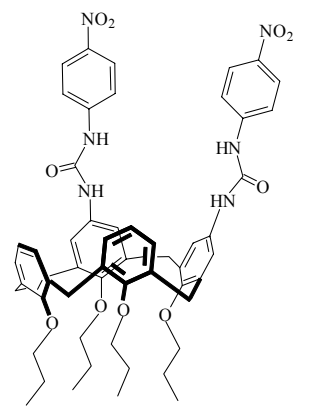

67
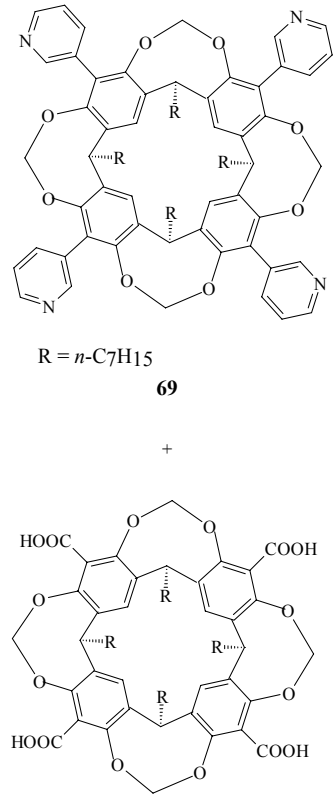

$\mathrm{R}=n-\mathrm{C}_{7} \mathrm{H}_{15}$

68
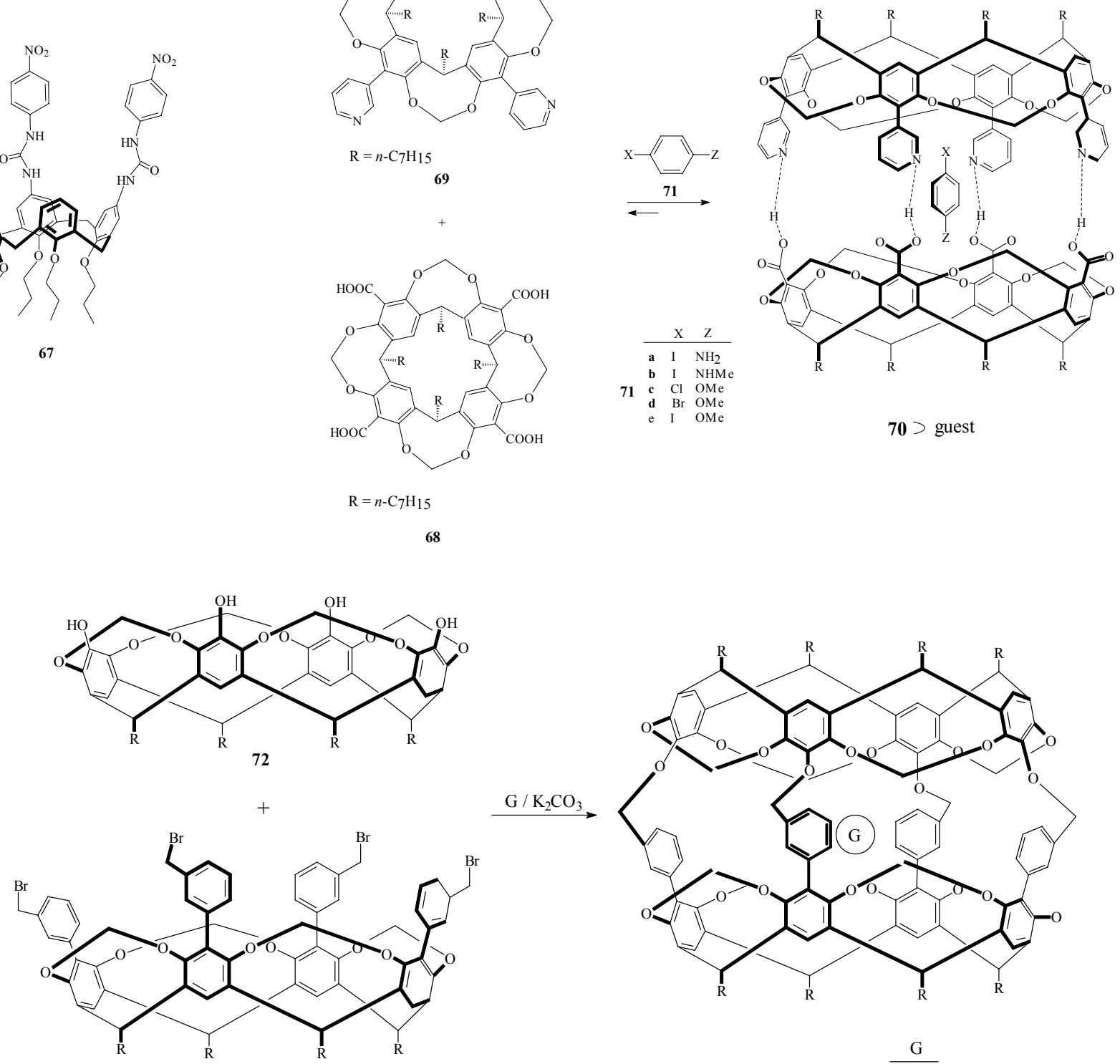

$\mathrm{G} / \mathrm{K}_{2} \mathrm{CO}_{3}$

$\mathrm{R}=n-\mathrm{C}_{7} \mathrm{H}_{15}$

73

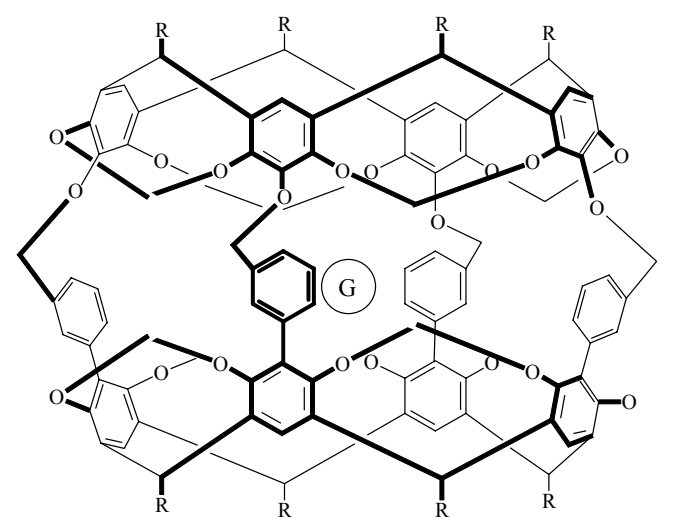

$\begin{array}{lll}74 & \supset \text { DMF } & \text { DMF } \\ 74 & \supset \text { DMA } & \text { DMA }\end{array}$ 

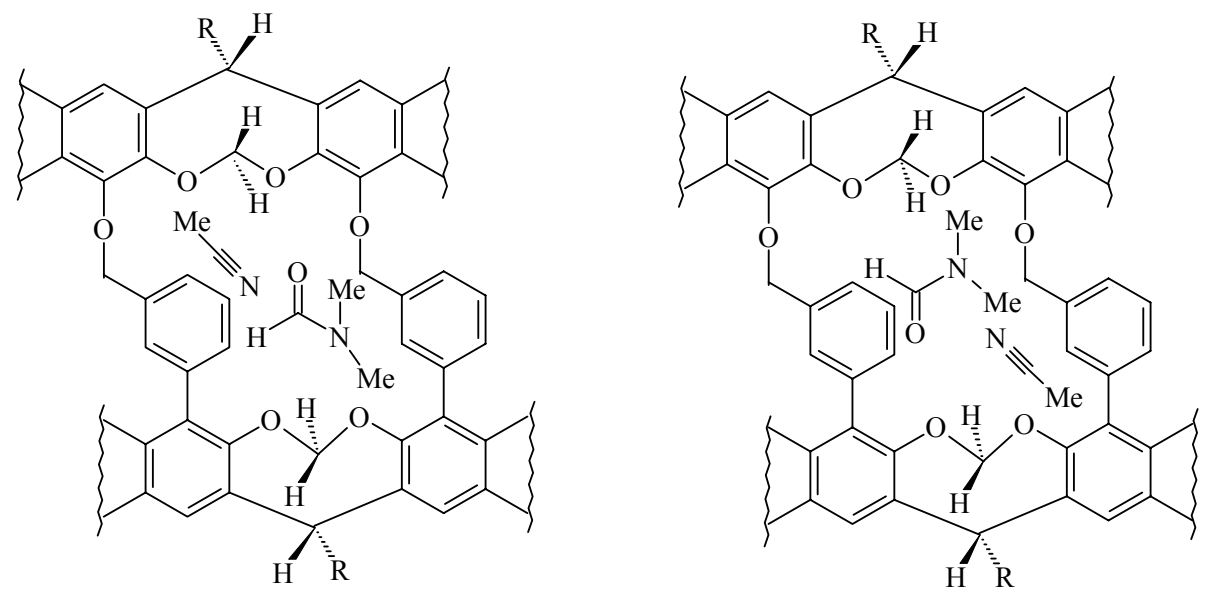

$74 \supset(\mathrm{DMF}+\mathrm{MeCN})$

major carceroisomer

minor carceroisomer

\section{Scheme 7}

\section{Conclusions}

The chemistry of capsules is developing rapidly; since the number of works concerning this class of compounds is very large ${ }^{50-64}$, in the above review only selected examples are described. The paper does not deal with capsule-like compounds ${ }^{65-67}$ nor with calixarene based nanotubes ${ }^{68-70}$.

Although the review is not exhaustive, the reported works highlight to some extent the most important properties of capsules and show possibilities of their use.

\section{References}

1. Koblenz, T. S.; Dekker, H. L.; de Koster, C. G.; van Leeuwen, P. W. N. M.; Reek, J. N.H. Chem. Commun. 2006, 1700.

2. Rudkevich, D. M.; Xu, H. Chem. Commun. 2005, 2651.

3. Makha, M.; Raston, C. L.; Sobolev, A. N.; White, A. H. Chem. Commun. 2005, 1962.

4. Śliwa, W. J. Inclusion Phenom. Macrocycl. Chem. 2005, 52, 13.

5. Śliwa, W. Khim. Get. Soedin. 2004, 805.

6. Śliwa, W. Croat. Chem. Acta 2002, 75, 131.

7. Śliwa, W. Heterocycles 2001, 55, 181.

8. Śliwa, W. Calixarene Pedagogical University of Częstochowa 2000, 116.

9. Śliwa, W.; Zujewska, T.; Bachowska, B. Polish J. Chem. 2003, 77, 1079. 
10. Śliwa, W.; Matusiak, G.; Deska, M. Heterocycles 2002, 57, 2179.

11. Śliwa, W,; Deska, M. Khim. Get. Soedin. 2002, 740.

12. Śliwa, W. Polish J. Chem. 2001, 75, 921.

13. Śliwa, W. Heterocycles 2002, 57, 169.

14. Liu, Y.; Warmuth, R. Angew. Chem. Int. Ed. 2005, 44, 7107.

15. Shivanyuk, A. Tetrahedron 2005, 61, 349.

16. Menozzi, E.; Busi, M.; Ramingo, R.; Campagnolo, M.; Geremia, S.; Dalcanale, E. Chem. Eur. J. 2005, 11, 3136.

17. Rebek, Jr. J. Angew. Chem. Int. Ed. 2005, 44, 2068.

18. Purse, B. W.; Gissot, A.; Rebek, Jr. J. J. Am. Chem. Soc. 2005, 127, 11222.

19. Azov, V. A.; Schlegel, A.; Diederich, F. N. Angew. Chem. Int. Ed. 2005, 44, 4635.

20. Palmer, L. C.; Zhao, Y.-L.; Houk, K. N.; Rebek, Jr. J. Chem. Commun. $2005,3667$.

21. Rissanen, K. Angew. Chem. Int. Ed. 2005, 44, 3652.

22. Warmuth, R.; Makowiec, S. J. Am. Chem. Soc. 2005, 127, 1084.

23. Sánchez Carrera, S.; Kerdelhué, J.- L.; Langenwalter, K. J.; Brown, N.; Warmuth, R. Eur. J. Org. Chem. 2005, 2239.

24. Liddell, M. J.; Margetic, D.; Mitchell, A. S.; Warrener, R. N. J. Comput. Chem, 2004, 25, 542.

25. Kaanumalle, L. S.; Gibb, C. L. D.; Gibb, B. C.; Ramamurthy, V. J. Am. Chem. Soc. 2005, $127,3674$.

26. Barrett, E. S.; Sherburn, M. S. Chem. Commun. 2005, 3418.

27. Mansikkamäki, H.; Schalley, C. A.; Nissinen, M.; Rissanen, K. New J. Chem. 2005, 9, 116.

28. Raston, C. L.; Cave, G. W. V. Chem. Eur. J. 2004, 10, 279.

29. Kuhnert, N.; Le-Gresley A. Org. Biomol. Chem. 2005, 3, 2175.

30. Shivanyuk, A.; Saadioui, M.; Broda, F.; Thondorf, I.; Vysotsky, M. O.; Rissanen, K.; Kolehmainen, E.; Böhmer, V. Chem. Eur. J. 2004, 10, 2138.

31. Haino, T.; Kobayashi, M.; Chikaraishi, M.; Fukazawa, Y. Chem. Commun. 2005, 2321.

32. Kaucher, M. S.; Lam, Y.-F.; Pieraccini, S.; Gottarelli, G.; Davis, J. T. Chem. Eur. J. 2005, $11,164$.

33. Harrison, R. G.; Burrows, J. L.; Hansen, L. D. Chem. Eur. J. 2005, 11, 5881.

34. Zuccaccia, D.; Pirondini, L.; Pinalli, R.; Dalcanale, E.; Macchioni, A. J. Am. Chem. Soc. 2005, 127, 7025 .

35. Cohen, T.; Avram, L.; Frish, L. Angew. Chem. Int. Ed. 2005, 44, 520.

36. Park, S. J.; Shin, D. M.; Sakamoto, S.; Yamaguchi, K.; Chung, Y. K.; Lah, M. S.; Hong, J.I. Chem. Eur. J. 2005, 11, 235.

37. Yamanaka, M.; Yamada, Y.; Sei, Y.; Yamaguchi, K.; Kobayashi, K. J. Am. Chem Soc. 2006, 128, 1531.

38. Yoshizawa, M.; Nakagawa, J.; Kumazawa, K.; Nagano, M.; Kawano, M.; Ozeki, T.; Fujita, M. Angew. Chem. Int. Ed. 2005, 44, 1810. 
39. Corbellini, F.; van Leeuwen, F. W. B.; Beijleveld, H.; Kooijman, H.; Spek, A. L.; Verboom, W.; Crego-Calama, M.; Reinhoudt, D. N. New J. Chem. 2005, 29, 243.

40. Corbellini, F.; Knegtel, R. M. A.; Grootenhuis, P. D. J.; Crego-Calama, M.; Reinhoudt, D. N. Chem. Eur. J. 2005, 11, 298.

41. Thallapally, P.K.; Lloyd, G.O.; Wirsig, T.B.; Bredenkamp, M.W.; Atwood, J.L.; Barbour, L.J. Chem. Commun., 2005, 5272.

42. Ananchenko, G. S.; Udachin, K. A.; Dubes, A.; Ripmeester, J. A,; Perrier, T.; Coleman, A. W. Angew. Chem. Int. Ed. 2006, 45, 1585.

43. Ananchenko, G. S.; Udachin, K. A.; Ripmeester, J. A.; Perrier, T.; Coleman, A. W. Chem. Eur. J. 2006, 12, 2441.

44. Dubes, A.; Udachin, K. A.; Shahgaldian, P.; Colemen, A. W.; Ripmeester, J. A. New J. Chem. 2005, 29, 1141.

45. Liu, R. S. H.; Hammond, G. S.; Acc. Chem. Res. 2005, 38, 396.

46. Lang, K.; Cuř́nová, P.; Dudič, M.; Prošková, P.; Stibor, I.; Št'astný, V.; Lhoták, P. Tetrahedron Lett. 2005, 46, 4469.

47. Kobayashi, K.; Ishii, K.; Yamanaka, M. Chem. Eur. J. 2005, 11, 4725.

48. Kobayashi, K.; Kobayashi, N.; Ikuta, M.; Therrien, N.; Sakamoto, S.; Yamaguchi, K. J. Org. Chem. 2005, 70, 749.

49. Ihm, C.; Jo, E.; Kim, J.; Paek, K. Angew. Chem. Int. Ed. 2006, 45, 2056.

50. Palmer, L. C.; Rebek, Jr.J. Org. Biomol. Chem. 2004, 2, 3051.

51. Pons, M.; Millet, O. Progress in NMR Spectr. 2001, 38, 267.

52. Aakeröy, C. B.; Schultheiss, N.; Desper, J. Org. Lett. 2006, 8, 2607.

53. Broda, F.; Vysotsky, M. O.; Böhmer, V.; Thondorf, I. Org. Biomol. Chem. 2006, 4, 2424.

54. Rudzevich, Y.; Fischer, K.; Schmidt, M.; Böhmer, V. Org. Biomol. Chem. 2005, 3, 3916.

55. Fujita, M.; Tominaga, M.; Hori, A.; Therrien, B. Acc. Chem. Res. 2005, 38, 369.

56. Fiedler, D.; Leung, D. H.; Bergman, R. G.; Raymond, K. N. Acc. Chem. Res. 2005, $38,349$.

57. Palmer, L. C.; Rebek, Jr. J. Org. Lett. 2005, 7, 787.

58. Baytekin, B.; Baytekin, H. T.; Schalley, C. A. Org. Biomol. Chem. 2006, 4, 2825.

59. Avram, L.; Cohen, Y. Org. Lett. 2006, 8, 219.

60. Gembus, A.; Corzilius, B.; Eichel, R.-A.; Dinse, K.-P.; Immel, S.; Stumm, D.; Flauaus, M.; Plenio, H. J. Phys. Chem. 2006, 110B, 15012.

61. Beyeh, N. K.; Kogej, M.; Åhman, A.; Rissanen, K.; Schalley, C. A. Angew. Chem. Int. Ed. 2006, 45, 5214.

62. Becker, R.; Reck, G.; Radeglia, R.; Springer, A.; Schulz, B. J. Mol. Struct. 2006, 784, 157.

63. Dolgonos, G.; Lukin, O.; Elstner, M.; Peslherbe, G. H.; Leszczynski, J. J. Phys. Chem. 2006, $110 \mathrm{~A}, 9405$.

64. Iwasawa, T.; Ajami, D.; Rebek, Jr. J. Org. Lett. 2006, 8, 2925.

65. Garozzo, D.; Gattuso, G.; Notti, A.; Pappalardo, A.; Pappalardo, S.; Parisi, M. F.; Perez, M.; Pisagatti, I. Angew. Chem. Int. Ed. 2005, 44, 4892.

66. Haino, T.; Matsumoto, Y.; Fukazawa, Y. J. Am. Chem. Soc. 2005, 127, 8936. 
67. Kerdpaiboon, N.; Tomapatanaget, B.; Chailapakul, O.; Tuntulani, T. J. Org. Chem. 2005, $70,4797$.

68. Organo, V. G.; Leontiev, A. V.; Sgarlata, V.; Dias, H. V. R.; Rudkevich, D. M. Angew. Chem. Int. Ed. 2005, 44, 3043.

69. Le Gac, S.; Zeng, X.; Reinaud, O.; Jabin, I. J. Org. Chem. 2005, 70, 1204.

70. Dalgarno, S. J.; Cave, G. W. V.; Atwood, J. L. Angew. Chem. Int. Ed. 2006, 45, 570. 